\title{
Rethinking Services with Communities of Color: Why Culturally Specific Organizations Are the Preferred Service Delivery Model
}

\author{
Ann Curry-Stevens ${ }^{1 *}$, Gerald Deloney ${ }^{2}$, Matt Morton ${ }^{3}$ \\ ${ }^{1}$ Faculty of Social Work, Wilfrid Laurier University, Kitchener, Canada \\ ${ }^{2}$ Formerly with Self Enhancement Inc., Portland, Oregon, USA \\ ${ }^{3}$ Meyer Memorial Trust, Portland, Oregon, USA \\ Email: *acurrystevens@wlu.ca
}

How to cite this paper: Curry-Stevens, A. Deloney, G., \& Morton, M. (2019). Rethinking Services with Communities of Color: Why Culturally Specific Organizations Are the Preferred Service Delivery Model. Sociology Mind, 9, 183-206. https://doi.org/10.4236/sm.2019.93013

Received: March 6, 2019

Accepted: June 10, 2019

Published: June 13, 2019

Copyright $\odot 2019$ by author(s) and Scientific Research Publishing Inc. This work is licensed under the Creative Commons Attribution International License (CC BY 4.0).

http://creativecommons.org/licenses/by/4.0/

\begin{abstract}
Racial disparities in social, education and health services continue unabated despite efforts to address them. At the margins of the service delivery system are lesser-known and minimally researched programs known as "culturally specific organizations" that have been developed by and with communities of color. These are organizations that have been developed by a specific community of color and continue to serve that same community of color. This article shares the insights of three leaders in racial equity, who have been immersed in Portland-based organizations for many years: two as organizational leaders and one as an academic research partner. The paper details the organizational assets, the research that provides emerging evidence of their contributions, and the resistance faced by its advocates. Additionally, original qualitative research contributes to this article: insights of the lived experience of leaders of color, and notes gathered over the years of presentations and dialogues in the region have been analyzed. Three additional assets are identified, adding to the seven assets that emerged in the literature. The article closes by identifying the implications that such organizations hold for education, research and practice.
\end{abstract}

\section{Keywords}

Alternative Organizations, Racial Disparities, Cultural Competency, Ethnic Agencies, Racial Equity, Social Service Organizations

\section{Introduction}

Over the last ten years, a quiet battle has simmered over the service delivery 
models being used to deliver health, education and social services in Multnomah County, Oregon, where Portland is located. Led by the Coalition of Communities of Color, a pan-racial coalition, and its twenty member organizations-each of whom is a culturally specific organization-there is growing tension as the Coalition has gained influence and leverage to affect the funding environment and service delivery methods used to reach communities of color (including African American, Native American, Latino, Asian and Pacific Islander, and racialized newcomers). Challenged are the conventions that have led to mainstream organizations having majority influence and power, and dominance on the service delivery landscape, and challenged specifically are mainstream organizations who are seeing the balance of power shift, as well as the funding bodies and philanthropic sector who are being asked to give stronger priority to funding culturally specific organizations.

We write this article as a partnership of two leaders of color and an academic who have been working together closely for seven years. Curry-Stevens has been the principal investigator in a seven-year community-based participatory research project with the Coalition of Communities of Color, where Deloney and Morton were members. Over these years, Deloney was the leading representative for Self Enhancement, Inc. which serves African American youth and families, and Morton was the Executive Director of Native American Youth and Family Center.

This article aims to document the issues behind this movement, and to highlight the reasons for culturally specific organizations to become the preferred model of service delivery for local communities of color. The literature also refers to these organizations as "ethnic agencies" or "ethno-specific organizations" (Iglehart \& Becerra, 1996; Holley, 2003). A synthesis of the philosophy, theory, existing literature and research is, to date, missing and is a gap the authors intend to fill. We also take this opportunity to begin to detail local experiences with culturally specific organizations.

There are implications for higher education where service providers are prepared for their respective fields in health, education and wider social services. These professions have emphasized that service staff can become equipped to practice across contexts and communities, regardless of one's identity, and all social service organizations can meaningfully serve the full range of communities. This text suggests that such a stance is an over-promise, and that we need to invest in services that are culturally specific, and where we better prepare students of color to work within their own communities. We caution the reader who finds this to be a form of segregation to withhold judgment until the arguments are outlined.

This article begins with the context of racial inequity, the dominant approaches used, the emergence of culturally specific organizations, and a synthesis of two dimensions of the literature: the theoretical advances embodied within culturally specific services, and the research findings on the benefits and challenges of such services. We then detail our local research with culturally specific 
services and organizations, and close with a summary of the features and assets that such services provide for the landscape of health, education and social services.

\section{The Context of Racial Disparities and Major Responses}

The failure of mainstream organizations to eliminate racial disparities in the outcomes of communities of color compels us to write this article. The imperative that emerges from disparities is that what we are doing is not working. Both locally in Oregon and nationally, disparities are pronounced. Local research (Curry-Stevens, Cross-Hemmer, \& Coalition of Communities of Color, 2010) identifies that pronounced disparities exist across 28 different systems and institutions, ranging from child welfare to homeownership to political representation. Nationally, disparity reports emerge many times a year, focusing on sectors such as juvenile justice, income, bankruptcy, environment, foundation funding and more.

The two major responses to disparities are 1) working towards cultural competency for service providers, and 2) systemic organizational change approaches (Curry-Stevens \& Nissen, 2011). Neither approach has provided significant gains. While much has been written to critique cultural competence (Curry-Stevens \& Nissen, 2011; Paasche-Orlow, 2004; Pon, 2009; Sakamoto, 2007), these arguments will not be summarized here-with the exception of their collective conclusion: that cultural competence does not provide a solution to racial disparities. We simply ask that readers acknowledge the shortcomings of cultural competence, and also that of anti-oppressive and even anti-racism practice-that white service providers and white mainstream organizations simply need to be better at working across racial lines to be effective. Further, this approach implicitly affirms the value of white workers to work effectively and optimally with communities of color. We ask readers to hold some suspicion about the degree to which this is possible, and in that space of ambiguity, open to the message of this article which legitimates culturally specific organizations as the preferred service delivery model.

Leading equity advocates Bell \& Ridolfi chastised the entire disparity sector when they published, "Adoration of the question" (2008), suggesting we study the problem without ensuring the results are available. This was extended by Shaw-Ridley \& Ridley (2010) as they identified the ethical violations embedded in the creation of a disparity reduction sector that has become a billion dollar industry with few gains experienced by service users and their communities, and with a protocol of remuneration that is not contingent on benefits accruing to the community. As Brach \& Fraser (2000) note, "we found the literature on racial and ethnic disparities weak on identifying the sources of disparities, and almost no attention has been paid to techniques for reducing them. Researchers have generally focused on rigorously documenting disparities and offered only speculative explanations for their findings" (p. 184). 
Time and again, mainstream organizations make promises to serve communities of color. Unfortunately, few are held accountable for how well these promises are actualized, and fewer still routinely disaggregate their service reports by race so we rarely know service outcomes for communities of color. Three notable exceptions to identifying disparities are the following federal agencies:

- Juvenile justice's detention practices were mandated by the federal government in 1992 and expanded in 2002 to address all aspects of youth encounters with the justice system, requiring that disparities be identified at numerous decision points that signify entry into the system and getting more deeply into the system;

- Statewide, child welfare agencies were mandated in 2007 through the Child and Family Services Review to report compliance with federal commitments to protecting children from harm once they had entered the child welfare system, though not requiring action on disparity reduction. Such mandates are the responsibility of the state, and Oregon's governor issued an executive order in 2009 to study and establish plans to eliminate racial disparities;

- The education system, under No Child Left Behind legislation in 2001, and subsequently by the Every Student Succeeds Act in 2015 similarly became required to identify racial disparities in achievement, although the policy has not resulted in closing these gaps, nor was it designed to achieve this.

Few improvements have resulted from these enhanced reporting requirements, unless the organization is part of a systems-wide change effort, well-resourced and led by organizations such as the Casey Foundation and the Burns Institute, which have a track record of significant investments in a few child welfare and juvenile justice institutions. While these efforts have been effective in establishing conditions to support racial equity, there is, as yet, scant evidence that such investments have reduced disparities or improved the lives of clients or communities of color.

What if we were to take seriously the critique that faces cultural competency and systems change approaches and become open to a new discourse: that neither mainstream organizations nor white service providers are able to adequately navigate these challenges? What then do we do? To answer this question, let us begin with explaining and detailing the emergence of culturally specific services.

\section{Culturally Specific Organizations Defined and Historicized}

In 2002, Multnomah County, Oregon, formally accepted the following definition of culturally specific organizations into policy, according to adherence with the following standards:

- Majority of agency clients served are from a particular community of color.

- Organizational environment is culturally focused and identified as such by clients.

- Prevalence of bilingual and/or bicultural staff reflects the community that is served. 
- Established and successful community engagement and involvement with the community being served.

This definition has been retained for the last 14 years, and expanded with the following in 2014:

- The staff, board, and leadership reflect the community being served.

- The community being served recognizes the organization as a culturally specific organization.

The history of such service provision is tied to the shortcomings of "one size fits all" approaches to services. The majority of culturally specific organizations have emerged due to the failure of mainstream organizations to effectively serve communities of color. The Afrocentric schools movement arose to rectify the alarming levels of racial disparities in the education system, including the achievement gap, the discipline gap, the graduation gap as well as overrepresentation in special education and underrepresentation in gifted programs and advanced academic courses (Dei, 2006; Pedroni, 2007; Shockley, 2007; Shockley \& Frederick, 2010; Dragnea \& Erling, 2008). Similarly, Native American schooling has been essential for addressing the dropout crisis facing Native children and youth (Faircloth \& Tippeconnic, 2010; Fryberg, Covarrubias, \& Burack, 2013), and Islamic schools are emerging in Australia in response to the marginalization such students experience in mainstream education (Gulson \& Webb, 2012). In health care, culturally specific services emerged to address the underuse of services by immigrants and communities of color (Goh, Low, \& Brodaty, 2010), to address the social exclusion of clients of color in AIDS organizations (Catungal, 2013), to rectify the inequalities of access to psychiatric services and the inaccurate assessment practices that emerge for communities of color (Bhui \& Sashidharan, 2003), and in diabetes care where communities of color have later diagnoses, poor diabetes control, greater complications, more emergency room visits and higher levels of hospitalization (Glazier, Kennie, Bajcar, \& Willson, 2006). Culturally specific residential services for aging populations have similarly emerged due the importance of seniors' reliance on socialization and relationships for wellbeing-and thus shared languages and cultures promote wellbeing (Goh, Low, \& Brodarty, 2010; Runci, Eppingstall, \& O’Connor, 2012; Radermacher, Feldman, \& Browning, 2009; Daker-White, Beattie, Gilliard, \& Means, 2002).

In Multnomah County, Oregon, this sector has seen some remarkable achievements. As noted earlier, racial disparities abound. Portland Public Schools (2019) holds a graduation rate for Native American youth at 40.6 percent and for African American youth at 70.6 percent, while that of white youth is 83.4 percent, and overall a rate of 79.6 percent, which is third worst in the nation. As a result of pervasive failures in educating youth of color, these two communities have developed their own culturally specific schools: Native American Youth and Family Center (NAYA) and Self Enhancement, Inc. (SEI). Recent graduation rates of these two schools are 72 percent and 98 percent respectively. These results surpass those of culturally specific schools published else- 
where (Dei \& Kempf, 2013) suggesting that there are additional features of practice that are offered in our local experiences that might hold lessons for culturally specific programing elsewhere in the nation.

With our own outcomes profiled, it is incumbent on us to share the existing research findings about culturally specific organizations. In short, they have a relatively thin yet highly promising research base, as is next detailed.

\section{The Research Evidence of the Benefits and Challenges of Culturally Specific Organizations}

Discourses, theoretical sophistication, power politics and philosophy aside, what evidence exists of the benefits of such programs? To answer this, we turn to the published literature as well as local experiences with such services. The literature in this area is relatively thin and eclectic, yet it illuminates some promising features of culturally specific services. The literature shows the value of such services in meeting the needs of communities of color, both in terms of improving individual health and well-being outcomes and also in terms of improving social capital by engaging in community development and systemic advocacy. The benefits of culturally specific services cover the following domains: improving client retention, longer periods of service engagement, reduced pathologizing of distress (lesser reliance on the medical model of services), affirming racial identity and pride, more holistic interventions, and greater involvement in systems change that adds upstream interventions, collectively working to improve client outcomes.

To ground this section, we begin by identifying the research that articulates the inadequacy of mainstream provider capacity to well serve communities of color. In a meta-review of the research into factors that inhibit positive outcomes for clients of color (and review of 309 titles, with 54 articles included in the study), Scheppers, van Dongen, Dekker, Geertzen \& Dekker (2006) synthesize provider-level barriers to effectively serving clients of color in the health field. They detail the following problems: insensitivity to the cultural norms of the patient, too much focus on the immediate issue (and missing the broader context of distress), little ethnic matching, weak communication skills, stereotypes that result in withholding of pain medications (citing Diaz, 2002, in Scheppers et al., 2006), inability to discern mental disorders from complex social distress, discourteous care, discrimination, authoritative communication styles, impersonal approaches, mono-lingualism, lack of cultural knowledge, inadequate translation, denial of spiritual elements, refusal to incorporate family and kin, and attitudes about the superiority of one's own beliefs.

Research studies on the outcomes of culturally specific interventions begin with three large comparative studies which found that culturally specific services provide better outcomes for clients of color in the following areas: lower drop-out rates from services, increased willingness to return for services, fuller use of services, and increased length of service engagement (Hohman \& Gait, 2001; Takeuchi, Sue, \& Yeh, 1995; Yeh, Takeuchi, \& Sue, 1994). Such services are 
understood to be more holistic, focusing less on the treatment of individual "pathologies" and more likely to understand racism as central to the experiences of people of color (Takeuchi, Sue, \& Yeh, 1995; Uttal, 2006). Furthermore, Uttal adds that cultural-specificity helps clients avoid sticking out as "other" and thus provides a culture of inclusion for clients of color.

Though much smaller, comparison research of Latinas in recovery programs with Latina-specific and mainstream services (134 and 57 participants, respectively) showed that women in culturally specific recovery homes were much more likely to successfully graduate, and much more likely to be established in permanent housing than their counterparts in mainstream recovery homes (Hohman \& Gait, 2001). Furthermore, those with the worst outcomes-dropping out having made unsatisfactory progress-were more than doubly frequent in mainstream settings. Since recovery from addiction has been tied to length of stay in recovery, the researchers conclude that culturally specific services are essential for the recovery prospects for Latinas with substance abuse issues. They interpret that cultural inclusion and values affirmation are key to these successes. Snowden, Hu \& Jerrell (1995) similarly identified that clients involved with culturally specific health services relied less heavily on emergency room visits, and also identified that ethnic matching similarly reduce reliance on the emergency room.

When looking at more organization-wide research (as opposed to intervention programs), features of culturally specific service organizations include the following: hiring staff from the same ethnic and linguistic community as service users, include community practices in supporting the individual, engaging in community development to increase cultural pride, decrease isolation and exclusion, encourage cultural consciousness, build power, address issues of racism, locate services in the community and offer holistic programming (Gillam, 2009; Uttal, 2006; Holley 2003). Gillam (2009) also describes culturally specific services as collaborating with service users to design services, resulting in higher user satisfaction.

Delving deeper into why mainstream services are less likely to achieve positive outcomes takes us into the notion of the client-worker "match." The research illustrates that a "match" between the identity of workers and clients has a positive impact on client outcomes. This match leads to fewer premature departures, increased use of services, improved mental health outcomes and life skills functioning, and being retained in services for longer periods of time (Hohman \& Gait, 2001). Further, Yamamoto, Silva, Justice, Chang \& Leong (1993) show that a colonial history of hostile relationships between the client and worker serves to contaminate the work with tension and mistrust, providing an additional service barrier.

Foregrounding the assessment process as integral to effective outcomes for communities of color, research identifies that many instruments used by mainstream health and social services are culturally inappropriate (Dana, 2010). Most tools set inappropriate norms among communities of color (such as excessive 
valuation of independence), and many tools do not have cross-cultural validity (Paniagua, 2005). One not-uncommon example is that experiences of racism, when retold to the White practitioner, are likely to be perceived as unreasonable feelings of persecution or even self-grandiose beliefs (Ridley, Li, \& Hill, 1998), leading to racial disparities in their treatment.

Additional mental health research also suggests that there is bias in the treatment regimes provided to those of different races. Lagomasino, Stockdale \& Miranda (2011) conducted a study of 58,826 outpatient visits to physicians and psychiatrists and disaggregated diagnostic results by the race of the client. Findings showed that Latino clients were less likely to be referred to counseling and Black and Latino clients were less likely to receive medication for depression or anxiety, and more likely to receive no care. While the provider-level data was not disaggregated by race, providers were implicated as holding racial bias in how they listened to, understood and responded to client concerns.

Bias exists in conventional tools, in the social service provider, and in the context under which services are provided (the setting itself). Time and again, the literature illustrates the "tendency to equate socio-cultural differences with deficiencies or abnormalities, [leading to] the exclusion of members of these groups from educational and employment opportunities and inappropriate labeling/classification" (Ridley, Li, \& Hill, 1998: p. 829). White practitioners typically do not understand the cultural and racial dimensions of the experiences of clients of color, and miss the multitude of microaggressions enacted upon communities of color, and in this misrecognition, have a greatly narrowed prognosis for building productive working relationships (Sue, 2010). Additional disservice is created by failing to understand coping strategies and forms of resistance that people of color use to preserve and protect themselves and their communities. Spiritual beliefs and use of traditional healers can be mistaken by white service providers as evidence of psychopathology (U.S. Department of Health \& Human Services, 2001).

Language accessibility deepens the over-diagnosis problem. There is a persistent pattern of over-diagnosis of clients of color who do not have strong English language skills. When clients are not interviewed in their own language, they are more likely to receive a more severe psychiatric diagnosis, to not comply with the therapist's recommendations, and to drop out of treatment (Seijo, Gomez, \& Freidenberg, 1991).

Culturally specific services are also more likely to emphasize the impact of macro-level policies and stressors on individuals. They focus less on individual "pathologies" to explain distress and are more likely to understand distress exacerbated or worsened by racism, discrimination, unfair treatment and damaging ideas about communities and people of color. In addition, communities of color prefer interventions that provide tangible supports to address immediate problems (Boyd-Franklin, 1989; Walker \& LaDue, 1986). When service providers share the background and identities of those they serve, they are less likely to 
"trespass" on the respectful recognition of individuals and communities (Rossiter, 2001). Moreover, even the context of administering tests serves to influence performance outcomes. When whites administer IQ tests to African Americans, their test scores fall (Jenkins \& Ramsay, 1995, as cited in Paniagua, 2005). In addition, interviews conducted in a language that is not one's native language tends to increase errors and diagnostic labels are accentuated (Marcos, 1976, as cited in Paniagua, 2005).

When we recall that one of the assets of culturally specific services is its integrated relationship with the community, we understand that research on the importance of service user voice in creating responsive and accountable organizations is relevant as part of the evidence base of culturally specific organizations. Although studied in a non-racialized context, Schweitzer (2011) identified that the top priority for reforms to services for runaway and homeless youth was accountability to the community served, articulated as "youth voice."

In summary, injury occurs when practitioners frame issues outside of their cultural context, and when distress is pathologized instead of understood in the context of broader systems of injustice and discrimination. Iglehart \& Becerra $(1996,2007)$ emphasize that mainstream services have broadly and widely failed communities of color through neglect and through the issues discussed above related to the shortcomings of white service providers in providing culturally-sensitive practice. We believe that more shortcomings of mainstream services will be identified as researchers add to this relatively scant body of literature.

With these outcomes in evidence, interest about culturally specific organizations is piqued: their potential to provide vastly improved services to people of color is an essential counterbalance to the questions within mainstream organizations about how to address disparities. As we will see in the next section on what the literature reveals about these organizations and their outcomes, the emerging evidence should be a missive to expand these alternate organizations in the service landscape.

\section{The Literature: Seven Assets of Culturally Specific Services}

A core question emerges about how we can synthesize the assets that culturally specific organizations manifest. Sevenkey features emerge from the literature. While these assets have been built within literature that is connected to culturally specific organizations, they have yet to be afforded the status of "evidence based." We urge the field not to discount them but rather understand they reflect the lived realities of culturally specific service providers, many of whom were former service users. This synthesis has been confirmed by the dialogues that have occurred at the Coalition of Communities of Color for more than a decade.

1) Inclusivity as opposed to "outsider" status. The first is the construct that mainstream services are unable to create an inclusive space for clients and 
communities of color, as they are infused with white-centrism as opposed to being neutral or open spaces for culture to be created and recreated by service users, while simultaneously under a guise of a "difference-blind approach ... [that can be] attributed to the liberal universalism which assumes that 'people are essentially the same"” (citing Henry et al., 2006 in Guo \& Guo, 2011: p. 68). Such dynamics exist despite the desire to infuse our geography with "the romantic discourse of urban diversity being trafficked in multicultural discourse" (p. 255), and, we add, a discourse of being progressive (as is the situation with our local region). Clients enter service spaces looking to see whether or not they belong, thereby rendering one to be an insider or an outsider to that space. As phrased by Catungal (2013), clients have a practice of "actively reading space for similar people: a means of gauging whether one is in a space of belonging” (p. 252). Catungal asserts that mainstream spaces are spaces of white dominance, and cannot fail to be memories of "colonial sites .... where the racist violence of sovereign imperial powers was meted out on colonized peoples" (p. 254), albeit in its more contemporary form of "racialized neglect and are therefore also violent" (p. 255). In this way, identity is forged by the degrees of similarly with one's surroundings, and when discordant, and particularly when rendered "other" to a context laden with imperial overtones, one is functionally excluded from the possibility of inclusion and acceptance. Culturally specific services thus emerged as a separatist space where they "deliberately come to exist as a way to redress social hierarchies in ways that are not possible in the mainstream" (Browne, 2009, as cited in Catungal, p. 259), and they become-under the leadership of the community-"spaces for mutual support, community building, and culturally specific services and programming $\ldots$ actively contesting the color-blindness of the mainstream. It is also, therefore, an incredibly political space" (p. 262).

Experience tells us that the key difference is that students of color enter the doors as insiders instead of outsiders. In spaces where their culture predominates, they are welcomed into spaces that affirm their identity, that are staffed by people who look like them and share their history. The asset of belonging is one that is a pronounced experience that is becoming recognized as a basic need, and a powerful force that diminishes the "othering" that is pronounced within race relations (Powell \& Menendian, 2016). Entering such organizations result in having one's culture and identity validates, rather than diminished as in conventional services. These students learn a curriculum that reflects their culture and receive education in a culturally-appropriate manner where there is prideful recognition of the community's history and accurate naming of the dynamics of racism, colonization and U.S. imperialism that has harmed the community. Additionally, the daily aggressions created by being a person of color in white society (as powerfully detailed by Sue, 2010) are minimized while these students are in such spaces, affording them a respite from racism.

2) Integration with the Community Served. Because culturally specific or- 
ganizations have been created by and for local communities of color, and are staffed by community members, they have deep ties with the community. Community members are more likely to be staff, and staff are more likely to be community members. This integration is both philosophical and experiential, ensuring that services are reflective of community interests and priorities. In addition, they retain a dynamic relationship with the community. Some historic features of the emergence of culturally specific organizations help account for this dynamism, including routine practices of being "otherized" by mainstream society. Early beginnings included being marginally positioned in the funding landscape, with very precarious fundraising options due to racism infused the seeking of funds: "providing services 'with no pay, no money, no profile' ... I was rejected by every single funder in town because we're Chinese" (Woo-Paw, cited in Guo \& Guo, 2011: p. 70). Furthermore, communities of color primarily inherited racial identities from state policies (Catungal, 2013). One of the consequences of this history is that communities of color in the USA tend to be committed to a more dynamic understanding of both identity and need, particularly in services for newcomers. Guo \& Guo (2011) interpret that organizations serving immigrants and other communities of color "found it necessary to constantly shift their priorities and reinvent themselves in response to immigrants changing needs" (p. 75). This nimble response to changing local needs is also a feature of the composition of staff and boards of directors. Being very likely to include high levels of community members in the organization's ranks simultaneously renders the organization likely to intimately know about and comprehend changing local conditions, and to be dedicated to responding to such shifts much more organically than mainstream organizations.

The field of "service user voice" (Beresford, 2000; Butcher, 2008) emphasizes the importance of affording service users influence in an organization. Scholarship that unfolds in partnership with service users illustrates the necessity of situating knowledge and expertise in the service user, to supplement, modify or replace the convention of situating expert knowledge in the hands of staff and administrators. Such findings stretch into a shift away from professional knowledge to that of service user, and thereby shifting the epistemology that underpins social services. This position is particularly true when considering communities of identity such as communities of color. In essence, the supposition is that the experience of racism as an African American or Latinx provides staff with a much more accurate understanding of the usefulness of social services to address distress that has likely been caused by racism.

While the dominant discourse that service user knowledges are invalid or contaminated remains largely intact, such knowledge needs to be granted primacy as it is derived from being service users and subjects of services (Beresford, 2000). Growing out of dissatisfaction with paternalist and tokenizing involvement of service users in social services (Beresford, 2000), service users have claimed their voice to influence service delivery, have built social movements to 
advance enfranchisement, acceptance and respect, and have simultaneously built political power. Examples include the Mad Pride movement, and the persons with disabilities movement. The motto, "nothing about us without us" encapsulates these movements and their goals. This is, not coincidentally, one of the key commitments of the Coalition's research partnership with Portland State University: to ensure that both philosophy and practice advances accountability to communities of color, and to ensure that knowledge and expertise is situated in communities of color.

3) Advocacy Involvement. Such organizations are also more likely to be politicized and engaged in social action. While sometimes tentative in discarding fears of state retaliation, suppression or exclusion, most culturally specific organizations are politically active. From a theoretical perspective, since the experiences of communities of color include deep and enduring racism, engagement in ameliorating racist institutions, policies, practices and discourses is essential to the wellbeing of the community.

At a 2013 conference, Ladson-Billings (a leading scholar in educating African Americans) indicated the primary purpose of education was empowerment and liberation, rather than the acquisition of skills to get jobs. From her perspective, education needs to focus on building social and political consciousness at the community, national and global levels, with focus on what it means to live in a deeply divided society and building the practice of healing these divides. In this way, she amplified the need to build praxis in a politics of redistribution-a theory of social justice articulated by Fraser \& Honneth (2003). The extension to social services is that when the needs of communities of color are foregrounded, a larger mandate for justice comes naturally to the surface.

4) Holistic Response to Need. When the needs of specific communities of color are held central to the origins, lived experiences and purpose of an organization, the fullness of need is understood and subsequently embraced. Literature on Afrocentric and Native American schools amplifies that such education integrates civic, linguistic, spiritual, community and cultural philosophy as part of the key services and approaches (Dragnea \& Earling, 2008; Hopson, Hotep, Schneidler, \& Turenne, 2010; Fryberg, Covarrubias, \& Burack, 2013; Faircloth \& Tippeconnic, 2010; Shockley \& Frederick, 2010). Such schools also place high emphasis on community engagement and parental involvement, and draw effectively on local healers and elders to root programming in the histories and legacies of the community. Culturally specific organizations (in our experience) do not compartmentalize need, as is a dominant approach with mainstream organizations. Many mainstream organizations assert that "they don't do advocacy work" or they conduct strategic planning on how to build specializations or market segmentation so as to create a service niche. In one way or another, they seem to find ways to satisfy themselves that they are doing enough. Our experience of culturally specific organizations is that they are not satisfied with drawing a boundary around what they do. They stretch themselves to be more 
comprehensive, to be more holistic in responding to the range of individual and community needs that exist.

The community has been involved in creating the service, helping to design its elements and being involved in correlated activities. We know from the literature (Gillam, 2009; Holley, 2003) and certainly from both NAYA and SEI that advocacy practices to assist youth and their families in other areas of life are important features of service. Examples include supports for homeownership, access to energy support financing, school-based advocacy, support to access higher education, summer programming, culturally specific events and health care referral and advocacy are integral to their success. So too is advocacy for larger systemic reform an integral part of services.

5) Relationship, Respect and Recognition. Culturally specific organizations emphasize relationships as integral to their effectiveness. Holding a shared identity with client of color means that one shares language, culture and experience. In social work practice, these facilitate the creation of relationship that continues to be the essential feature of the ways that clients value social work services. O'Leary et al. (2013) confirm this stance: "The centrality and importance of the social work relationship has been consistently emphasized in the profession's literature for over a century" (p. 136, 2013). Beresford, Croft and Adshead (2008) also affirm the importance of relationship from the perspective of service users, alongside an equivalent focus on the nature of the relationship as one of "friendship ... associating this idea with ... two characteristics-reciprocity and flexible professional relationships" (p. 1394). Cooper \& Lesser (1997) articulate that clients of color "often find it difficult to convey their feelings to one who has not experienced the subtle, insidious and pervasive impact of racism" (p. 325). The inverse must hold that practitioners who share one's marginal identity are more likely to be accepted and experiences of racism more readily confirmed. Workers of color hold lived experiences to draw upon in terms of understanding what clients lives are likely to have been. In this space, understanding is deepened, opening the space for more authentic relationship and compassion to emerge. From the client's perspective, there is a greater likelihood to believe that the worker holds unconditional regard for the client.

Staff, in coming from the community, is understood to be "culture carriers" (T. Hopson Sr., personal communication, July 9, 2014). In this way, culture is embodied, and relationships thus are fertile spaces for having culturally affirming engagement between clients and their communities, and enacted in multiple ways when a client comes through the doors of a culturally specific organization. This manifests at the front desk, in the hallway, with educators, counselors, cafeteria workers and grounds maintenance staff. In other words, because identities are shared, and culture is embodied in staff, clients and community members have their cultural identities affirmed throughout their time in the organization. This asset has typically been invisible to funders, as the core service providers are those who are seen as important. This improved lens lets us see value 
throughout the organization.

This position can be stretched deeply when we consider how integral "respectful recognition" is to both social justice as well as community wellbeing. Advanced by Honneth (1996) as an essential ingredient for justice, his stance is that relationships that confirm experiences of injustice not only enhance psychological wellbeing (for one ceases to personalize a sense of inadequacy for being marginalized or oppressed), but extend to ameliorate othering and objectification, which serve themselves as forces of oppression, aptly described by Young (1990) as cultural imperialism. In this way, Honneth asserts that relationships that are embedded in respect, and that bring a politicized understanding to experience serve to advance social justice in ways that preserve the dignity of the entire community. As synthesized by Houston (2013), the psychosocial affirmations create outcomes that build confidence, self-respect and self-esteem, and diminish the harmful effects of misrecognition. With misrecognition (which in this context includes the omission of a politicized lens on experience) comes exclusion, isolation, emotional neglect and ignoring the value of one's personal and collective identity. For readers who wrestle with the seemingly divergent ways in which Fraser \& Honneth (2003) speak about social justice, culturally specific organizations engage in both a politics of redistribution (through their advocacy practice) and recognition (through the relational engagement with clients and their communities).

6) Having Tied Futures. Critical forms of social work practice have long-held that the profession needs to be deeply involved in changing power relationships and advocating for broader social change (Moreau, 1979, among many others). Recently, writing from Fay (2011) asserts that social workers should aspire to stand in solidarity with clients and their communities, and work from the position of having "shared liberation." The problem, however, in our interpretation, is that if we are completely honest about what it takes for workers and their organizations to truly have our liberation tied with that of those we serve, then we need to conclude that the workers who are truly able to make such commitments are workers of color. It is only this group that holds tied futures to the liberation of social work clients and communities. Here is a demonstration: if racism can be eradicated, then clients, communities, and workers of color mutually benefit. If disparities in the education system can be dismantled, and racial profiling by police officers eliminated, and discriminatory practices by landlords to renting to applicants of color, then all people of color will benefit, regardless of one's positional privilege or lack thereof. In this way, community success is truly tied to the liberation of workers of color. This is a considerable asset in social work practice. No stretches needed, no counterintuitive understanding of liberation is needed, and no additional empathy required to be built and sustained. Quite simply, the liberation across the population becomes a mandate for practice that taps into the assets of workers and clients of color alike.

7) Sidestepping Imperial Roles and Relationships. The nation's history in 
racism includes older demonstrations of genocide, slavery, and forced assimilation, and more current versions of discrimination and racial inequities such as the school-to-prison pipeline, unjust immigration laws, labor exploitation, and institutional racism in many forms. Writing about the colonial encounter between a volunteer in a soup kitchen and an indigenous man receiving soup, Rossiter (2001) decries the ways that trespass and disrespect are communicated in the typical social work encounter, not by intent but rather by presuming that the encounter is simply about serving soup, and obliterating the racist history that gives rise to such need and response. When an imperialized body provides services to a colonized other, the relationship and justice possibilities are narrowed. And when that encounter is within a mainstream organization that reproduces inequities and disparities, injustice is enacted. When services are provided by and with those who share identities, the imperial dimension of the relationship is diminished.

The literature thus gives rise to seven key insights that help explain the benefits of culturally specific organizations. We turn now to identifying, through our own research process, additional benefits not yet seen in the literature. This work begins with an overview of the methodology used.

\section{Research Methodology}

Over the seven years of meeting on a research project to detail and advocate to address racial disparities facing local communities of color, the co-authors of the project were engaged in a range of presentations and conversations regarding the situation facing communities of color more broadly. Often, policy makers, funders, and community leaders asked members of the Coalition of Communities of Color to share their perspectives of how their organizations were benefiting their clients, so these generated a range of insights over numerous years. Extensive notes were taken by the academic partner in this project (additionally the first author), and this became the data for subsequent analysis. In addition, focused dialogues with the co-authors of our experiences within culturally specific organizations expanded these data.

The academic partner conducted a thematic analysis of the approximately 120 pages of notes gathered over the years, aiming to discern the core assets that leaders working in culturally specific organizations experienced. While this is a non-conventional qualitative research undertaking, there are a few features that strengthen its trustworthiness: prolonged engagement over seven years of such dialogues, triangulation across different contributors and contexts of meetings, and member checking with Coalition members regarding the insights garnered from the data. Overall, these findings are deeply informed by the experience of members of the Coalition of Communities of Color, who had given voice to their experiences in culturally specific organizations. The insights gathered are next detailed, remembering that, as yet, these are new contributions to the literature. 


\section{Research Findings}

From our own research based on the narratives generated through a range of dialogues over seven years, three additional assets emerged and subsequently detailed.

Respite from Racism. Inclusive spaces, full of people who share one's identity provide not only the opportunity for culturally affirming encounters, but also spaces that serve as a respite from racism. While racism cannot stop fully at the doors of culturally specific organizations, it can be curtailed by racially affirming experiences. In this way, culturally specific organizations offer a time to recoup from the day-to-day indignities that people of color face in mainstream society, and to have a break from its relentlessness. For all the reasons why respite care is available in many service organizations, respite from stress and strain enhances one's long-term ability to cope with injustice.

Speed of Trust. Culturally specific organizations manifest what can best be named as "speed of trust" (Covey, 2006). When clients see that their worker shares their identity, there is a speedy extension of trust that moves from the societal level to the relational level. The opposite racial encounter makes this clearer-when a client of color sees that their worker is white, distrust and suspicion rise. Concerns about whether they will be understood, whether they will be shamed, whether they will be judged; suspicion as to whether the engagements will be useful emerges. In this way, the societal trust one has in one's community is endowed on the individual worker of color. This hastens the transmission of trust, which makes for more efficient relationship development, and therefore expands productive engagement.

Social and Economic Capital. Culturally specific organizations stretch their influence into the fiber of the community: building valued community resources which become a form of social capital to be drawn upon both now and into the future. Such capital grows as community members develop their own solutions to issues and build capacities to tackle future issues. So too local leaders are developed among Board members, advisors, staff and volunteers. At the same time, local knowledges grow and flourishes as the community builds expertise, influence and a correlated positive reputation for meeting community needs. These activities create ripple effects, achieving what Beresford cites as "recognition [being] given to the validity of the subjective knowledges, analyses and perspectives" of community members (2000: p. 501). The investment in communities of color to develop and expand culturally specific services also becomes a form of economic capital as both a place of employment (essential as income, unemployment and occupational segregation are deeply disparate for communities of color) and an anchor for future economic growth. Such investments serve to stabilize a community.

Most importantly, however, is that culturally specific services are invested in building institutions that are successful for communities of color. The investments in success are rooted in the shared identity of service provider and service 
user-when the Native American community operates a school for its own youth, the success of these youth benefits the community at large and the investments are those that flow from a shared identity. Consider on the other hand what investments exist for mainstream service providers: the investments for white people in the success of communities of color are typically fleeting or as Deloney states, "the flavor of the month." The problem flows from identity and kinship-if the school system (for example) does not work for my children, my neighbor's children and my hairdresser's children, then my objection, my anger and my response will be immediate, deeply rooted and profound. If the school system does not work for people I do not know nor interact with in daily life, then my upset will be muted and fleeting: not the sort of reaction that will catalyze real reforms.

Worse still is that there is a real possibility that institutional disparities and inadequacies might even work to benefit white folk-by allowing the better grades and scholarships to be available to White youth, or the better jobs and promotions to be available to Whites. A parallel may be found in the justice system, in that imprisoning more people of color lets Whites retain both an ethos of superiority and real democratic power-the impact of removing thousands from voting entitlements keeps elected power whiter (Alexander, 2010). By extension, white people can actually be invested in sustaining inequities because the benefits of privilege are retained instead of shared. Communities of color must, therefore, gain control over services on which they depend.

Does this narrative mean that organizations that are not culturally specific cannot build these assets? No, but not easily, is our conclusion, and not deeply. Standing on the other side of an imperial identity, and a dominant/marginal power hierarchy places severe constraints on an ability to build such organizations. We encourage organizations aspire to this, and at the same time, want to inspire the full range of professional service providers (education, health, social services) to acknowledge these assets and promote culturally specific organizations as a more promising organizational model to address racial disparities.

\section{Resistance to Culturally Specific Services}

Resistance to culturally specific services has been pronounced. In Canada, the creation of an Afrocentric public school was perceived as a form of segregation; a harsh reminder of more racist eras in history, and perceived to be a reversal of progress towards racial equity. Challenges to that perspective are numerous. The depth of this challenge takes on a profound dominant discourse that implicitly suggests such organizations are disloyal to a vision of the nation state. Says Guo and Guo (2011), "ethno-specific organizations are often criticized for threatening national unity, diluting [Canadian] identity, and promoting ghettoization and separatism" (p. 60). That expansive critique suggests this movement is damaging to both mainstream and culturally specific communities alike. George Dei-Canada's leading advocate for Afrocentric schools-beseeches us to dis- 
tinguish between "separation by choice" and "forced segregation" of prior eras (1996: p. 72). Locally, Oregon's advocates emphasize the importance of education for attaining the prospects of rising out of poverty and/or building a self-determining future: "we are trying to get our children to adulthood with as intact set of options as possible" (G. Deloney, personal communication, September 6,2013$)$. When mainstream schooling fails to graduate $1 / 2$ to $2 / 3$ of our students of color, the urgency to build alternatives cannot be underestimated.

It is, admittedly, a loss for us (particularly for whites who want to focus on the last decades of gains in policy and human rights) to face the fact that racial equity is still a distant dream. While we grieve over the need for alternative service models, remember that we do not equally bear the injury of these failed systems. Communities of color struggle to pick up the pieces of lives compromised, families torn apart, and futures narrowed. When leaders of color emphasize the importance of alternatives, we collectively need to listen and respond.

Some resistance is more racist. Movements to add Islamic schools in Australia have been opposed by the public and also by local governments, positioning culturally specific education as a sign of rejecting Australian identity: "The ones that come here oppress our society, they take our welfare and they don't want to accept our way of life" (McCulloch, as cited in Gulson \& Webb, 2012: p. 703). When such schools were denied space, local governments provided "techno-rational grounds" (ibid) such as traffic concerns.

Other forms of resistance are more sympathetic with the experiences of clients of color. In work that seeks to build the best of both approaches, Radermacher, Feldman \& Browning (2009) amplify earlier works by Fuller (1997) and Barnett (1988), and seek to advance an approach that is not "either-or" but rather "both-and," suggesting that multicultural services can be provided in mainstream institutions. Caution is urged with this approach. Multiculturalism does not hold power relationships (and more importantly, power hierarchies) central to an analysis of the exclusion and marginalization of clients of color-rather, it suggests the issue is one of difference, and that appreciation and learning about "other" will provide sufficient affirmation of identity and experience. Our position is that it will not. Multicultural approaches to practice, while an improvement on colorblind approaches, leaves out issues of racism and the political imperative to notice and affirm (and resist) such experiences.

Local resistance to such services cannot be separated from local arrangements of power. Considerable vested interests exist for school districts, local governments and large health and service organizations to resist the development of such organizations. Building such services redistributes financial resources, visibility and voice-removing some financing from the conventional recipients of these benefits, who are mainstream services. While we might be positioning the region for a net economic benefit if we graduate more students of color, build stronger career paths for our most marginalized communities, create a healthier population, and redirect youth away from the child welfare or criminal justice 
system, the more immediate impact is that funders' budgets will be shared more equitably and diminishing the budgets of mainstream service providers. Hiding behind philosophical arguments is not an acceptable response or a tactic that will engender collective health and wellbeing.

\section{Recommendations for the Field}

The implications for the field are significant. The first is that we need to "trouble" (Ellsworth, 1997 as cited in Kumashiro, 2001) our beliefs that if white practitioners simply learn well enough how to work with clients of color, then racial disparities can be ameliorated. "Troubling" refers specifically to disrupting a dominant discourse and challenging a status quo that replicates inequity. The disparities field has promised much but failed to significantly improve outcomes for communities of color. Social work educators and practitioners need to hold much greater ambivalence about the promises embedded in cultural competence, anti-oppressive practice, and even anti-racism practice. Whenever we suggest that white practitioners can be effective in cross-cultural settings, we undermine the evidence that suggests this approach might be less fruitful than we anticipate.

Second, we need to legitimate the unique contributions of culturally specific organizations in social work education and practice. In education, we need to integrate this practice model into our teaching, and need to identify more practicum opportunities in such spaces. It also means that we need to better recruit and support students of color in higher education, and establish pathways into the university that are accessible to community members who intend to return to their communities and help improve wellbeing. Building such pathways will increase the likelihood that students of color will be equipped for professional roles in culturally specific organizations. In practice, we need to expand funding available for such interventions, ideally be etching larger portions of available funds to such organizations. Simultaneously, we need to heighten expectations for mainstream organizations to report three key success measures in disaggregated ways: access, retention and client outcomes. Only then will we be able to see if equity is enacted in service provision.

Third, research needs to be available for culturally specific organizations to build the evidence base of their practice. Ensuring that the increased attention to both culturally responsive program evaluation and practice-based evidence is inclusive of culturally specific organizations is key for ensuring that the promise of culturally specific organizations receives support from the field. A local example is a collective impact initiative being funded by United Way of Columbia and the Willamette. Successful Families 2020 is in the midst of a school improvement effort done in deep partnership with four culturally specific organizations to support the academic and life success of students of color. A quasi-experimental evaluation study of the initiative aims to better understand the features of culturally specific interventions that can be credited with student success. 
Fourth, the insights in this article hold potential to be generalized to other axes of identity, such as the disability and LGBTQ communities. While this article focuses on culturally specific organizations to advance racial equity, similar arguments and evidence are likely to align for advancing a parallel set of services in additional communities.

A final comment may help the reader address what might be an unresolved concern, and perhaps offer an appropriate closure for this paper: does such a direction mean that the promise of racial integration has failed? In response, it is not a failed concept or a failed vision, but rather that it is a failed promise that too many people of color have been denied, and who we must no longer require to wait. Wherever possible, culturally specific organizations must be supported to provide a viable alternative to ensure that we do not fail another generation of people of color. Communities of color must not be asked to wait while mainstream institutions take an all-too-slow journey towards racial equity.

\section{Conclusion}

Culturally specific organizations hold potential to improve outcomes in fields where clients and communities of color face considerable racial disparities. They are important contributors to the service landscape and it is important that they continue to receive attention in research, in higher education, in preparation of service providers, and in funding. To fully embrace these innovations, we need to "trouble" dominant discourses about mainstream institutions and service providers who are from the dominant culture. Being skeptical of the ability of mainstream service providers and their institutions to provide effective and respectful service is a more fertile stance to enter such considerations. It is time to lessen our collective grasp on what we think can work, and enter serious consideration of more innovative alternative models.

\section{Conflicts of Interest}

The authors declare no conflicts of interest regarding the publication of this paper.

\section{References}

Alexander, M. (2010). The New Jim Crow: Mass Incarceration in the Age of Colorblindness. New York: The New Press.

Barnett, K. (1988). Aged Care Policy for a Multicultural Society. Australian Journal on Ageing, 7, 3-21. https://doi.org/10.1111/j.1741-6612.1988.tb00334.x

Bell, J., \& Ridolfi, L. (2008). Adoration of the Question: Reflections on the Failure to Reduce Racial \& Ethnic Disparities in the Juvenile Justice System. San Francisco, CA: W. Haywood Burns Institute.

Beresford, P. (2000). Service Users' Knowledge and Social Work Theory: Conflict or Collaboration? British Journal of Social Work, 30, 489-503.

https://doi.org/10.1093/bjsw/30.4.489

Beresford, P., Croft, S., \& Adshead, L. (2008). "We Don't See Her as a Social Worker": 
The Importance of the Social Worker's Relationship and Humanity. British Journal of Social Work, 38, 1388-1407. https://doi.org/10.1093/bjsw/bcm043

Bhui, K., \& Sashidharan, S. (2003). Should There Be Separate Psychiatric Services for Ethnic Minority Groups? British Journal of Psychiatry, 182, 10-12. https://doi.org/10.1192/bjp.182.1.10

Boyd-Franklin, N. (1989). Black Families in Therapy: A Multisystems Approach. New York: Guilford.

Brach, C., \& Fraser, I. (2000). Can Cultural Competency Reduce Racial and Ethnic Health Disparities? A Review and Conceptual Model. Medical Care Research and Review, 57, 181-217. https://doi.org/10.1177/1077558700057001S09

Browne, K. (2009). Womyn's Separatist Spaces: Rethinking Spaces of Difference and Exclusion. Transactions of the Institute of British Geographers, 34, 541-556. https://doi.org/10.1111/j.1475-5661.2009.00361.x

Butcher, H. (2008). Service User Involvement in Cancer Care: Policy, Principles, Practice. London: National Cancer Action Team.

Catungal, J. (2013). Ethno-Specific Safe Houses in the Liberal Contact Zone: Race Politics, Place-Making and Genealogies of the AIDS Sector in Global-Multicultural Toronto. ACME International Journal of Critical Geography, 12, 250-278.

Cooper, M., \& Lesser, J. (1997). How Race Affects the Helping Process: A Case of Cross Racial Therapy. Clinical Social Work Journal, 25, 323-335.

https://doi.org/10.1023/A:1025738629237

Covey, S. (2006). The Speed of Trust: The One Thing That Changes Everything. New York: Free Press.

Curry-Stevens, A., \& Nissen, L. (2011). Reclaiming Futures Considers an Anti-Oppressive Frame to Enhance Effectiveness in Decreasing Disparities. Children and Youth Services Review, 33, 54-59. https://doi.org/10.1016/j.childyouth.2011.06.013

Curry-Stevens, A., Cross-Hemmer, A., \& Coalition of Communities of Color (2010). Communities of Color in Multnomah County: An Unsettling Profile. Portland, OR: Portland State University.

Daker-White, G., Beattie, A., Gilliard., J., \& Means, R. (2002). Minority Ethnic Groups in Dementia Care: A Review of Service Needs, Service Provision and Models of Good Practice. Aging and Mental Health, 6, 101-108. https://doi.org/10.1080/13607860220126835

Dana, R. (2010). Culturally Competent Assessment Practice in the United States. Journal of Personality Assessment, 66, 472-487. https://doi.org/10.1207/s15327752jpa6603_2

Dei, G. (1996). Beware of False Dichotomies: Revisiting the Idea of "Black-Focused" Schools in Canadian Contexts. Journal of Canadian Studies, 31, 58-79. https://doi.org/10.3138/jcs.31.4.58

Dei, G. (2006). Black-Focused Schools: A Call for Re-Visioning. Education Canada, 46, 27-31.

Dei, G., \& Kempf, A. (2013). New Perspectives on African-Centered Education in Canada. Toronto, ON: Canadian Scholars' Press.

Dragnea, C., \& Erling, S. (2008). The Effectiveness of Africentric (Black-Focused) Schools in Closing Student Success and Achievement Gaps: A Review of the Literature. Toronto: Toronto District School Board.

Faircloth, S., \& Tippeconnic, J. (2010). The Dropout/Graduation Crisis among American Indian and Alaska Native Students: Failure to Respond Places the Future of Native Peoples at Risk. Los Angeles, CA: The Civil Rights Project/Proyecto Derechos Civiles at 
UCLA.

Fay, J. (2011). Let Us Work Together: Welfare Rights and Anti-Oppressive Practice. In D. Baines (Ed.), Doing Anti-Oppressive Practice: Social Justice Social Work (2nd ed., pp. 64-79). Halifax: Fernwood Publishing.

Fraser, N., \& Honneth, A. (2003). Redistribution or Recognition? A Political-Philosophical Exchange. London: Verso.

Fryberg, S., Covarrubias, R., \& Burack, J. (2013). Cultural Models of Education and Academic Performance for Native American and European American Students. School Psychology International, 34, 439-452. https://doi.org/10.1177/0143034312446892

Fuller, J. (1997). Multicultural Health Care: Reconciling Universalism and Particularism. Nursing Inquiry, 4, 153-159. https://doi.org/10.1111/j.1440-1800.1997.tb00093.x

Gillam, T. (2009). Improving Services to African American Survivors from IPV: From the Voices of Recipients of Culturally Specific Services. Violence against Women, 15, 57-80. https://doi.org/10.1177/1077801208328375

Glazier, R., Kennie, N., Bajcar, J., \& Willson, K. (2006). A Systematic Review of Interventions to Improve Diabetes Care in Socially Disadvantaged Populations. Diabetes Care, 29, 1675-1687. https://doi.org/10.2337/dc05-1942

Goh, I., Low, L., \& Brodaty, H. (2010). Levels and Rates of Depression among Chinese People Living in Chinese Ethno-Specific and Mainstream Residential Care in Sydney. International Psychogeriatrics, 22, 237-245. https://doi.org/10.1017/S104161020999069X

Gulson, K., \& Webb, P. (2012) Education Policy Racialisations: Afrocentric Schools, Islamic Schools, and the New Enunciations of Equity. Journal of Education Policy, 27, 697-709. https://doi.org/10.1080/02680939.2012.672655

Guo, S., \& Guo, Y. (2011). Multiculturalism, Ethnicity and Minority Rights: The Complexity and Paradox of Ethnic Organizations in Canada. Canadian Ethnic Studies, 43, 59-80. https://doi.org/10.1353/ces.2011.0023

Hohman, M., \& Gait, D. (2001) Latinas in Treatment: Comparisons of Residents in a Culturally Specific Recovery Home with Residents in Non-Specific Recovery Homes. Journal of Ethnic and Cultural Diversity in Social Work, 9, 93-109. https://doi.org/10.1300/J051v09n03_05

Holley, L. (2003). Emerging Ethnic Agencies: Building Capacity to Build Community. Journal of Community Practice, 11,39-57. https://doi.org/10.1300/J125v11n04_03

Honneth, A. (1996). The Struggle for Recognition: The Moral Grammar of Social Conflicts. London: Polity Press.

Hopson, R., Hotep, U., Schneider, D., \& Turenne, I. (2010). What's Educational Leadership without an African-Centered Perspective? Explorations and Extrapolations. Urban Education, 45, 777-796. https://doi.org/10.1177/0042085910384201

Houston, S. (2013). Social Work and the Politics of Recognition. In M. Gray, \& S. Webb (Eds.), The New Politics of Social Work (pp. 63-76). London: Palgrave Macmillan. https://doi.org/10.1007/978-1-137-32712-3_4

Iglehart, A., \& Becerra, R. M. (1996). Social Work and the Ethnic Agency: A History of Neglect. Journal of Multicultural Social Work, 4, 1-20. https://doi.org/10.1300/J285v04n01_01

Iglehart, A., \& Becerra, R. M. (2007). Ethnic Sensitive Practice: Contradictions and Recommendations. Journal of Ethnic and Cultural Diversity in Social Work, 16, 43-63. https://doi.org/10.1300/J051v16n03_04

Kumashiro, K. (2001). "Posts" Perspectives on Anti-Oppressive Education in Social Stu- 
dies, English, Mathematics, and Science Classrooms. Educational Researcher, 30, 3-12. https://doi.org/10.3102/0013189X030003003

Lagomasino, I., Stockdale, S., \& Miranda, J. (2011). Racial-Ethnic Composition of Provider Practices and Disparities in Treatment of Depression and Anxiety, 2003-2007. Psychiatric Services, 62, 1019-1025. https://doi.org/10.1176/ps.62.9.pss6209_1019

Moreau, M. (1979). A Structural Approach to Social Work Practice. Canadian Journal of Social Work Education, 5, 78-93.

O'Leary, P., Tsui, M.-S., \& Ruch, G. (2013). The Boundaries of the Social Work Relationship Revisited: Towards a Connected, Inclusive and Dynamic Conceptualization. British Journal of Social Work, 43, 135-153. https://doi.org/10.1093/bjsw/bcr181

Paasche-Orlow, M. (2004). The Ethics of Cultural Competence. Academic Medicine, 79, 347-350. https://doi.org/10.1097/00001888-200404000-00012

Paniagua, F. (2005). Assessing and Treating Culturally Diverse Clients: A Practical Guide. Thousand Oaks, CA: Sage. https://doi.org/10.4135/9781483329093

Pedroni, T.C. (2007). Market Movements: African American Involvement in School Voucher Reform. New York: Routledge.

Pon, G. (2009). Cultural Competency as New Racism: An Ontology of Forgetting. Journal of Progressive Human Services, 20, 59-71. https://doi.org/10.1080/10428230902871173

Portland Public Schools (2019). Four and Five-Year Cohort Graduation and Completion Rates.

https://www.pps.net/cms/lib/OR01913224/Centricity/Domain/207/Grad\%20and\%20C ompletion\%20Rates\%20by\%20Subgroup\%202009-10\%20through\%202017-18.pdf

Powell, J., \& Menendian, S. (2016). The Problem of Othering: Towards Inclusiveness and Belonging. Othering and Belonging: Expanding the Circle of Human Concern, 2, 14-39.

Radermacher, H., Feldman, S., \& Browning, C. (2009). Mainstream versus Ethno-Specific Community Aged Care Services: It's Not an "Either or". Australian Journal on Aging, 28, 58-63. https://doi.org/10.1111/j.1741-6612.2008.00342.x

Ridley, C., Li, L., \& Hill, C. (1998). Multicultural Assessment: Reexamination, Reconceptualization and Practical Application. The Counseling Psychologist, 26, 827-910. https://doi.org/10.1177/0011000098266001

Rossiter, A. (2001). Innocence Lost and Suspicion Found: Do We Educate for or against Social Work? Critical Social Work, 2, 1-5.

Runci, S., Eppinstall, B., \& O’Connor, D. (2012). A Comparison of Verbal Communication and Psychiatric Medication Use by Greek and Italian Residents with Dementia in Australian Ethno-Specific and Mainstream Aged Care Facilities. International Psychogeriatrics, 24, 733-741. https://doi.org/10.1017/S1041610211002134

Sakamoto, I. (2007). An Anti-Oppressive Approach to Cultural Competence. Canadian Social Work Review, 24, 105-114.

Scheppers, E., van Dongen, E., Dekker, J., Geertzen, J., \& Dekker, J. (2006). Potential Barriers to the Use of Health Services among Ethnic Minorities: A Review. Family Practice, 23, 325-348. https://doi.org/10.1093/fampra/cmi113

Schweitzer, D. (2011). Runaway and Homeless Youth: Changing the Discourse by Legitimizing Youth Voice. Doctoral Dissertation.

Seijo, R., Gomez, J., \& Freidenberg, J. (1991). Language as a Communication Barrier in Medical Care for Hispanic Patients. Hispanic Journal of Behavioral Sciences, 13, 363-375. https://doi.org/10.1177/07399863910134001 
Shaw-Ridley, M., \& Ridley, C. (2010). The Health Disparities Industry: Is It an Ethical Conundrum? Health Promotion Practice, 11, 454-464. https://doi.org/10.1177/1524839910375612

Shockley, K. (2007). Africentric Education Leadership: Theory and Practice. International Journal of Education Policy \& Leadership, 3, 1-12.

Shockley, K., \& Frederick, R. (2010). Constructs and Dimensions of Afrocentric Education. Journal of Black Studies, 40, 1212-1233. https://doi.org/10.1177/0021934708325517

Snowden, L., Hu, T., \& Jerrell, J. (1995). Emergency Care Avoidance: Ethnic Matching and Participation in Minority-Serving Programs. Community Mental Health Journal, 31, 463-473. https://doi.org/10.1007/BF02188616

Sue, D. (2010). Microaggressions in Everyday Life: Race, Gender and Sexual Orientation. Hoboken, NJ: Wiley.

Takeuchi, T., Sue, S., \& Yeh, M. (1995). Return Rates and Outcomes from Ethnicity-Specific Mental Health Programs in Los Angeles. American Journal of Public Health, 85, 638-643. https://doi.org/10.2105/AJPH.85.5.638

U.S. Department of Health and Human Services (2001). Mental Health: Culture, Race and Ethnicity. A Supplement to Mental Health: A Report of the Surgeon General. Rockville, MD: Substance Abuse and Mental Health Services Administration, Center for Mental Health Services.

Uttal, L. (2006). Organizational Cultural Competency: Shifting Programs for Latino Immigrants from a Client-Centered to a Community-Based Orientation. American Journal of Community Psychology, 38, 251-262. https://doi.org/10.1007/s10464-006-9075-y

Walker, R., \& LaDue, R. (1986). An Integrative Approach to American Indian Mental Health. In C. Wilkinson (Ed.), Ethnic Psychiatry (pp. 146-194). New York: Plenum. https://doi.org/10.1007/978-1-4613-2219-1_5

Yamamoto, J., Silva, J., Justice, L., Chang, C., \& Leong, G. (1993). Cross-Cultural Psychotherapy. In A. Gaw (Ed.), Culture, Ethnicity and Mental Illness (pp. 101-124). Washington DC: American Psychiatric Press.

Yeh, M., Takeuchi, T., \& Sue, S. (1994). Asian American Children in the Mental Health System: A Comparison of Parallel and Mainstream Outpatient Service Centers. Journal of Clinical and Child Psychology, 38, 251-262. https://doi.org/10.1207/s15374424jccp2301_2

Young, I. (1990). Five Faces of Oppression. In Justice and the Politics of Difference (pp. 39-65). Princeton, NJ: Princeton University Press. 